\title{
Development of NaY zeolite derived from biomass and environmental assessment of carbon dioxide reduction
}

\author{
Patcharin Worathanakul ${ }^{1,2}$ and Patchaya Tobarameekul ${ }^{1}$ \\ ${ }^{1,2}$ Department of Chemical Engineering, Faculty of Engineering, King Mongkut's University of Technology North Bangkok, \\ 10800, Thailand \\ ${ }^{1}$ Center of Eco-material and Cleaner Technology, King Mongkut's University of Technology North Bangkok, 10800, Thailand
}

\begin{abstract}
Carbon dioxide is one of greenhouse gases. The carbon dioxide caused by the industry activities and impact to the global warming. The objectives of this research were to synthesize NaY zeolite from bagasse ash as silica source and loaded with different weight percentage of $\mathrm{Cu}(\mathrm{II})$ for carbon dioxide reduction. The carbon footprint of $\mathrm{Cu} / \mathrm{Y}$ zeolite for carbon dioxide reduction was calculated. The synthesized $\mathrm{NaY}$ zeolite from bagasse ash can be easily formed at $\mathrm{Si} / \mathrm{Al}$ ratio of 0.75 with the additional heat after crystallization $70{ }^{\circ} \mathrm{C}$ for 1 hour. The crystal size of $\mathrm{NaY}$ zeolite was approximately $0.22-0.37 \mu \mathrm{m}$ diameter. The results of carbon dioxide adsorption were increased when the flow rate of carbon dioxide decreased. Finally, the carbon footprint value was shown that synthesis step was shown the highest of greenhouse gas emission. This research can increase the value of wastes and reduce pollution emission.
\end{abstract}

\section{Introduction}

Global warming caused by greenhouse gases is a major environmental problem, and many efforts have been made to reduce their emission. The increase effects atmospheric $\mathrm{CO}_{2}$ is one of the greenhouse gases. Many researchers have suggested that $\mathrm{CO}_{2}$ emissions could be reduced by capturing using solvents [1], membranes [2] and solid absorbents [3]. However, liquid absorption method suffers from several drawbacks such as high regeneration energy, large equipment size, solvent degradation, and equipment corrosion [4].

To avoid the disadvantages of liquid absorption, solid adsorbent is one of alternative ways. Zeolite is a suitable candidate for $\mathrm{CO}_{2}$ adsorption because of its high surface area, thermal and mechanical stabilities. It is a hydrated aluminosilicate material that exhibits crystallinity and has a porous structure with large surface area.

There are many tools to address global warming problem and measure impact of each product on the environment. One of them is called "Carbon footprint assessment", carbon footprint assessment can also be information to determine an ability to manage the environmental impact of individual entrepreneurs, by using life cycle assessment method (LCA) of the product. The measurement and calculation of greenhouse gas emissions have been stated, that there are many activities such as electricity and water supply consumption, quantities of wastewater and garbage, and the amount of fossil fuels used causing greenhouse gas emission. Carbon footprint is one of tools to quantify and subsequently to GHGs emissions reduction [5]. It expressed as $\mathrm{CO}_{2}$ equivalents $\left(\mathrm{CO}_{2}\right.$-eq) but also carried out the hot spot of environmental impact of products cycles and can be used for production process improvement [6].

Generally sugar industry produced sugar only but the current sugar industry has become a combination of sugar mill, power plant and distillery, etc. which produce sugar, electricity and ethanol. In sugar mill, sugar is produced through several processes which are given below sugar milling, juice clarification and treatment, crystallization, centrifugal separation and drying [7].

Bagasse is by-product of sugar industry obtained after the extraction process. This by-product was used in different processes such as fuel resources [8] which sugarcane bagasse is burnt in the boiler, producing steam that is expanded in turbines coupled with electric generators [9] and silica source [10]. Bagasse ash is a general term describing all forms of the ash produced from burning bagasse. From large quantities of bagasse ash from industry lead to many researches to enrich its value for example, using bagasse ash to synthesize silica or to synthesize catalysts.

With good physico-chemical properties of zeolite for $\mathrm{CO}_{2}$ adsorption, zeolite $\mathrm{Y}$ or $\mathrm{NaY}$ is a highly versatile molecular sieve from the faujasite family of zeolites whose $7.4 \AA$, three-dimensional pore structure and solid acidity make it useful as a catalyst, ion exchanger, adsorbent, etc. Zeolite $\mathrm{Y}$ is commonly prepared with a high aluminum content, but in most cases it is employed in a silicon-enriched form [11].

The objective of this research was to develope porous materials at the nanometer scale for $\mathrm{NaY}$ zeolite synthesis using seeding method for $\mathrm{CO}_{2}$ reduction. Therefore, the production of $\mathrm{NaY}$ from bagasse ash was used $\mathrm{Si} / \mathrm{Al}$ ratio of 0.75 with different temperatures, times and weight percentages of ion exchange. The $\mathrm{CO}_{2}$ reduction of $\mathrm{NaY}$ from bagasse ash and carbon footprint assessment of products was evaluated the greenhouse gas emission throughout life cycle of products. Finally, ways to reduce energy consumption in the process for minimizing the environmental impact was studied.

\section{Methodology}

\subsection{Materials}

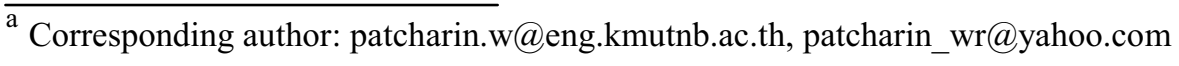


Silica and $\mathrm{NaY}$ zeolite adsorbent was prepared by reacting the following: bagasse ash obtained from a bagasse field in Thailand contained 96 wt.\% $\mathrm{SiO}_{2}, 0.98$ wt.\% $\quad \mathrm{Al}_{2} \mathrm{O}_{3}, \quad 0.77$ wt.\% $\quad \mathrm{K}_{2} \mathrm{O}$ and 0.13 wt.\% $\mathrm{Fe}_{2} \mathrm{O}_{3}$ (Khonburi Sugar Public Company Limited). Other materials used were; hydrochloric acid $(37 \mathrm{wt} \% \mathrm{HCl}$, Merck), sodium aluminate $\left(\mathrm{Al}_{2} \mathrm{O}_{3} 50-56\right.$ wt. $\% \mathrm{Fe}_{2} \mathrm{O}_{3} 0.05$ wt.\% and $\mathrm{Na}_{2} \mathrm{O}$ 40-45 wt.\%, Sigma Aldrich), sodium hydroxide (99 wt.\% NaOH, Merck), Sodium siligate $\left(\mathrm{Na}_{2} \mathrm{O} 18\right.$ wt.\% and $\mathrm{SiO}_{2} 63$ wt.\%, Sigma Aldrich), copper nitrate (99.5 wt.\% $\mathrm{Cu}\left(\mathrm{NO}_{3}\right)_{2} \bullet 3 \mathrm{H}_{2} \mathrm{O}$, Merck), distilled water, deionized water and carbon dioxide (Carbon dioxide : HP Grade, Linde)

\subsection{Silica extraction}

The impurities in bagasse ash can be reduced to using hydrochloric acid treated bagasse ash. Direct extraction of silica can be performed by stirring the sodium hydroxide solution and bagasse ash. During this process, silica is extracted in the form of sodium silicate together with other organic moieties. The sodium silicate obtained is converted to silica by solvent extraction method. The silica from bagasse ash in this sample ash was studied the effect of acid treatment.

\subsection{NaY zeolite preparation}

The seed gel was prepared first by adding the sodium silicate solution prepared from bagasse ash or silica colloid into sodium aluminate solution under stirring until homogenous. The feedstock gel was also prepared in the same way. The seed gel was then mixed into the feedstock gel. Synthesis of NaY zeolite was prepared with different temperatures and time. Ion exchange of the zeolite was then performed in different wt.\% of $\mathrm{Cu}\left(\mathrm{NO}_{3}\right)_{2} \cdot 3 \mathrm{H}_{2} \mathrm{O}$.
Chemical composition of bagasse ash was examined by X-ray fluorescence spectroscopy (XRF: Bruker AXS, Germany). The crystallinity was measured by X-ray diffraction analysis (XRD: Model $\mathrm{D}_{8}$ Advance, Bruker AXS, Germany). The surface areas of the zeolites were determined with Brunauer-Emmett-Teller (BET: (Autosorb 1C, Quantachrome, USA) analysis. A thermogravimetric analyzer (TGA: Netzsch 449F3) was used to measure the $\mathrm{CO}_{2}$ adsorption capacity and Scanning Electron Microscopy (SEM: JSM-7001F) were determined morphology and characteristics crystalline phase of the silica and $\mathrm{NaY}$ zeolite.

\subsection{Carbon footprint of $\mathrm{NaY}$ for $\mathrm{CO}_{2}$ reduction}

The Carbon footprint assessment consists of four main steps according to life cycle assessment method (LCA)

\subsubsection{Goals and scope}

The research boundary began from raw materials acquisition, $\mathrm{NaY}$ preparation, distribution, $\mathrm{CO}_{2}$ reduction and disposal step according to Business-to-Customer scope (Fig. 1). Input and output were mainly collected from laboratory data. It was assumed that there is no emission at the distribution stage. At the disposal stage, waste was assumed to be assigned to landfills. The functional unit was $0.3 \mathrm{~g}$ of $\mathrm{NaY}$ with $\mathrm{CO}_{2}$ reduction.

\subsubsection{Inventory analysis}

Inventory analysis is the methodological step where an overview is given of the environmental interventions caused by or required for the processes within the boundaries of the studied system. To collect and gather the information of an input-output substances quantity and energy used in each procedures of the $\mathrm{CO}_{2}$ reduction process in accordance with the target and the scope that were defined.

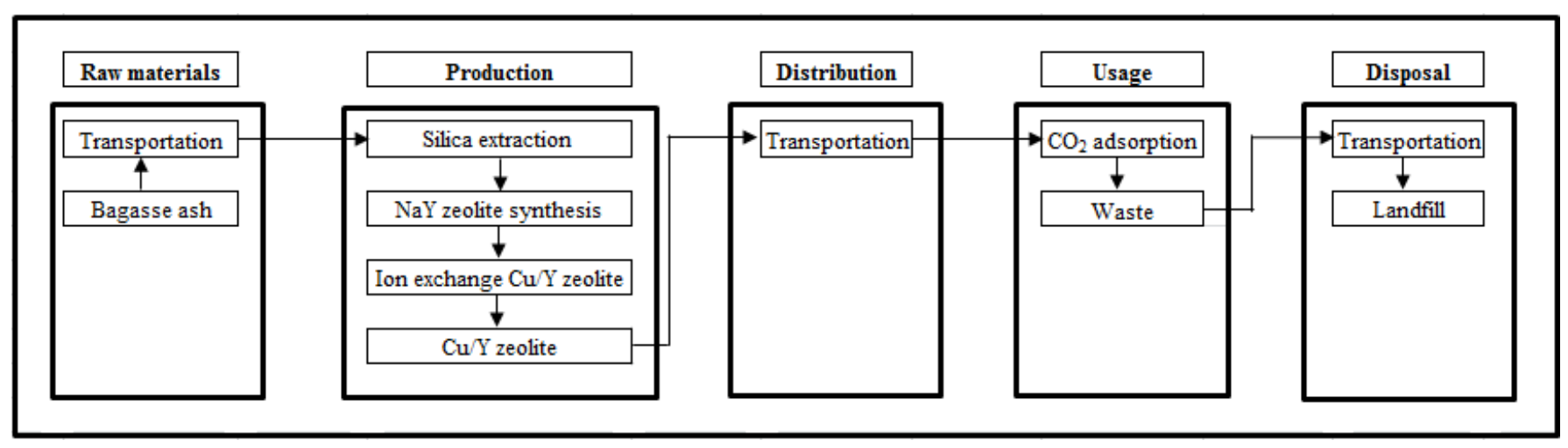

Figure 1. Boundary of $\mathrm{NaY}$ for $\mathrm{CO} 2$ reduction.

\subsection{Characterization analysis}

There are five steps including; acquisition of raw materials, $\mathrm{NaY}$ preparation, distribution, $\mathrm{CO}_{2}$ reduction and disposal steps. All materials were transported to the laboratory area. There is no transportation to distributors 
because of usage only in the laboratory. In the disposal stage, all waste was assumed to be transported to a landfill site.

\subsubsection{Impact Assessment}

Impact assessment examines the environmental burdens of the emissions and resource use quantified in the inventory analysis. The amount of greenhouse gases emissions for $\mathrm{NaY}$ production for $\mathrm{CO}_{2}$ reduction and its application was calculated in $\mathrm{kgCO}_{2}$-eq unit.

\subsubsection{Interpretation}

Interpretation was affected to environment concerns and gave information with the hot spot step. This step can be to reduce energy consumption in the process for minimizing the environmental impact. The identification of significant issues, conclusions and recommendations are made in this step, which can be changed and improved to the appropriate process in the future.

\section{Results and Discussion}

\subsection{Characterization of silica}

\subsubsection{Chemical composition of silica}

The composition of minerals leached from Bagasse ash was shown in Table 1. Found that silica production was composed of silicon dioxide the 92.64 wt.\% and other impurities by gross weight. However, the silica purity of the bagasse ash from acid-leached bagasse ash in this study was higher than directly from bagasse ash without leaching.

Table 1. Chemical composition of silica from bagasse ash.

\begin{tabular}{|c|c|c|}
\hline \multirow{2}{*}{ Chemical compositions } & \multicolumn{2}{|c|}{ Wt.\% } \\
\cline { 2 - 3 } & Directly & Acid-leached \\
\hline $\mathrm{SiO}_{2}$ & 77.81 & 92.64 \\
\hline $\mathrm{Al}_{2} \mathrm{O}_{3}$ & 14.40 & 0.81 \\
\hline $\mathrm{P}_{2} \mathrm{O}_{5}$ & 194.64 & 1.26 \\
\hline $\mathrm{Fe}_{2} \mathrm{O}_{3}$ & 191.38 & 2.34 \\
\hline $\mathrm{K}_{2} \mathrm{O}$ & 1.15 & 2.07 \\
\hline Others & 0.62 & 0.88 \\
\hline
\end{tabular}

\subsubsection{X-ray diffraction analysis (XRD) of silica}

Silica from bagasse ash in Fig. 2 was observed that, only a broad peak with $2 \Theta$ at 22 degree corresponds to the research of Mohamed, et al [11].

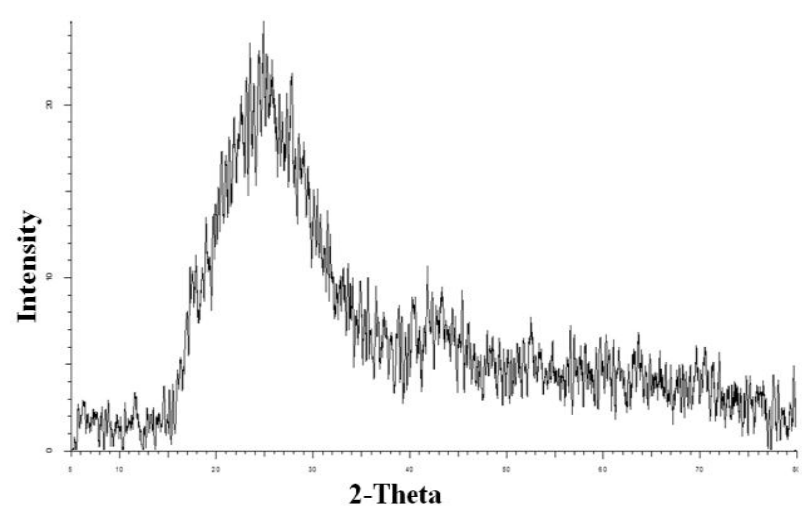

Figure 2. XRD patterns of silica from bagasse ash.

\subsubsection{Scanning Electron Microscopy (SEM) of silica}

From the SEM image showed the physical structure of silica in Fig. 3. It was found that amorphous shape. It was observed a characteristic of amorphous silica.

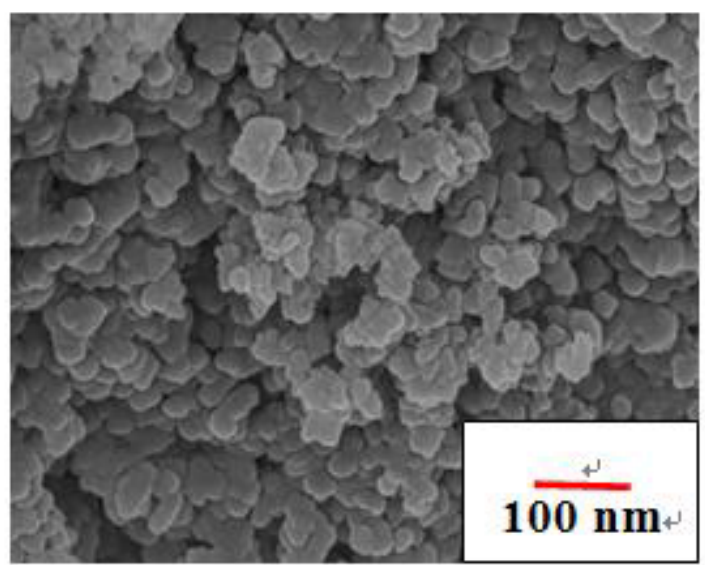

Figure 3. SEM of silica from bagasse ash.

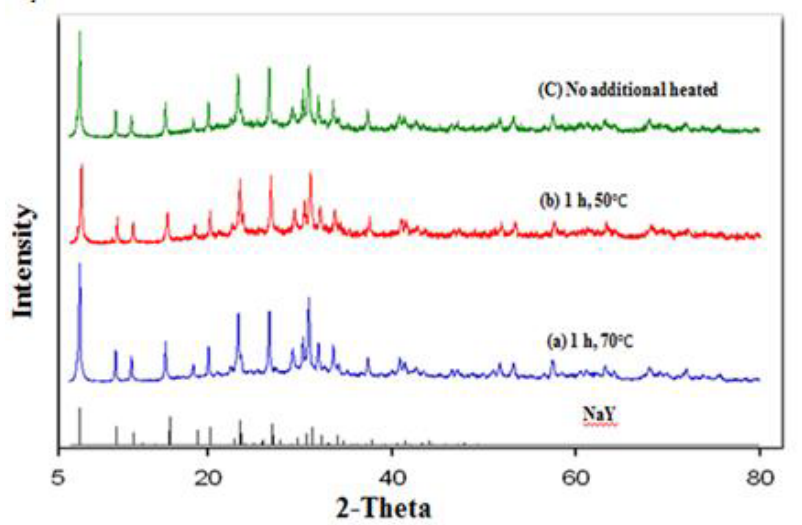

Figure 4. XRD patterns of $\mathrm{NaY}$ zeolite.

\subsection{Characterization of NaY zeolite}

\subsubsection{X-ray diffraction analysis (XRD) of NaY zeolite}

The synthesized NaY zeolite in Fig. 4 showed peaks corresponded to peaks standards [12]. In addition, the $\mathrm{NaY}$ zeolite was characterized by XRD compared with 
the patterns effect of temperature and time after crystallization. When the crystallization time was reduced from $24 \mathrm{~h}$ to $3 \mathrm{~h}$, it was found that the height of peaks was decreased. While there is no heating, the samples are amorphous structure due to decreases of crystallization rate.

\subsubsection{Scanning Electron Microscopy (SEM) of $\mathrm{NaY}$ zeolite}

Fig. 5 shows $\mathrm{SEM}$ image of $\mathrm{NaY}$ at $0.75 \mathrm{Si} / \mathrm{Al}$ with spherical shape. The crystal size of $\mathrm{NaY}$ was approximately $0.22-0.37 \mu \mathrm{m}$ diameter corresponds to the research of Rakpasert (2012) [13].

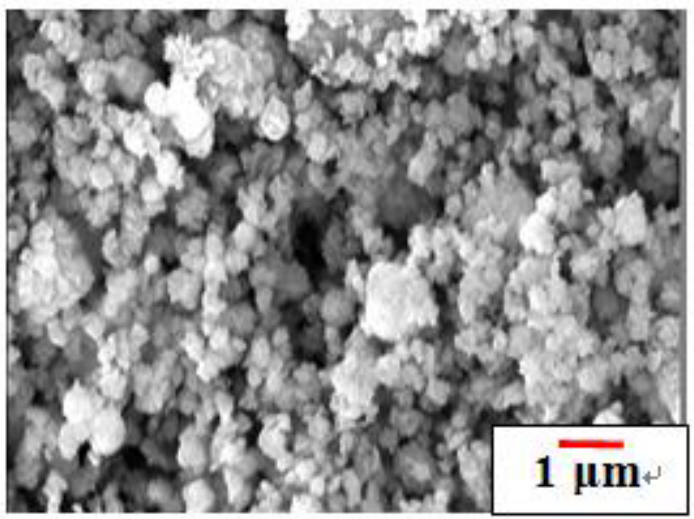

Figure 5. $\mathrm{SEM}$ of $\mathrm{NaY}$ with $\mathrm{Si} / \mathrm{Al}$ ratios of 0.75 with additional heat $1 \mathrm{~h}$ at $70^{\circ} \mathrm{C}$.

\subsubsection{Brunauer-Emmett-Teller (BET) of NaY zeolite}

BET surface area of $5.5 \mathrm{wt} \%$ of $\mathrm{Cu}$ loading to $\mathrm{NaY}$ was $52.33 \mathrm{~m}^{2} / \mathrm{g}$, total pore volume was $0.204 \mathrm{~cm}^{3} / \mathrm{g}$ and pore size was $18.2 \AA$. The increased surface area and total pore volume of $\mathrm{NaY}$ results in an increase in the number of adsorption sites for $\mathrm{CO}_{2}$ adsorption. The volume for trapping $\mathrm{CO}_{2}$ was determined by pore volume. The large amount of adsorption sites and the trapping volume led to the high $\mathrm{CO}_{2}$ capacity. In terms of pore, the micropore is more effective than the mesopore and macropore.

\subsection{Carbon footprint of zeolite for $\mathrm{CO} 2$ reduction}

Finally, the life cycle assessment of $\mathrm{Cu} / \mathrm{Y}$ zeolite was calculated for carbon dioxide reduction. The carbon footprint value was $14.84 \mathrm{~kg} \mathrm{CO}$-eq. Figure 6 shows percentage of carbon footprint in each stage which synthesis process of production stage was shown the highest of greenhouse gas emission. It came from energy consumption of incubator which was used in ion exchange procedure and $\mathrm{Cu} / \mathrm{Y}$ synthesis procedure. Secondary step is usage for $\mathrm{CO}_{2}$ reduction has GHG emission ratio equal to $26.9 \%$, followed by raw materials extraction and waste disposal respectively.

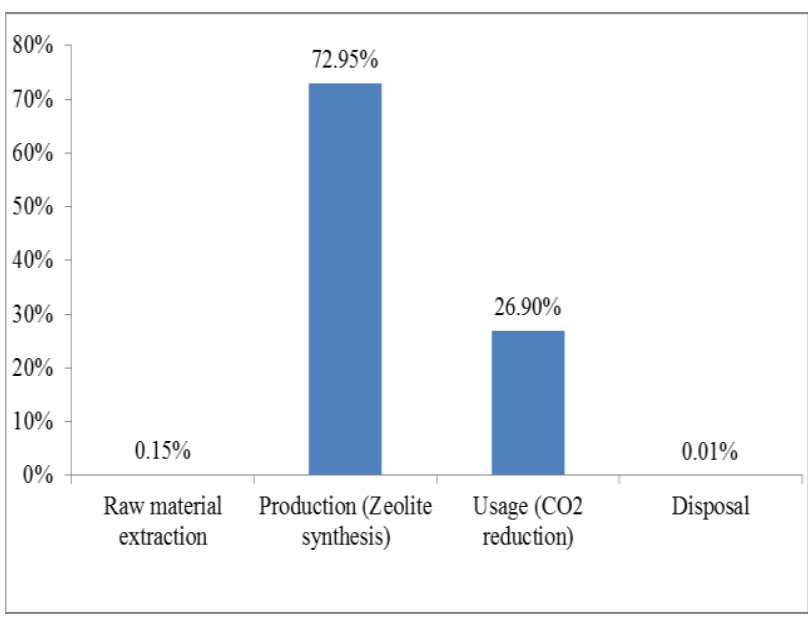

Figure 6. Percentage of carbon footprint in each stage.

\section{Conclusions}

The bagasse ash is well raw material in $\mathrm{NaY}$ zeolite particles synthesis. Physicochemical properties of the produced $\mathrm{NaY}$ zeolite after optimizing the various synthesis conditions were characterized. The optimum crystallization time for the synthesis of $\mathrm{NaY}$ zeolite with bagasse ash was $1 \mathrm{~h}$ at $70{ }^{\circ} \mathrm{C}$. The crystal size of $\mathrm{NaY}$ zeolite was approximately $0.22-0.37 \mu \mathrm{m}$ in diameter. Metals loading on $\mathrm{NaY}$ zeolite didn't alter the $\mathrm{NaY}$ structure. Therefore, the NaY with the large surface area, the total pore volume, and the micropore was the most favorable in the physical adsorption of $\mathrm{CO}_{2}$. The carbon footprint of $0.3 \mathrm{~g} \mathrm{NaY}$ with $\mathrm{CO}_{2}$ reduction was 14.84 $\mathrm{kgCO} 2$-eq. Synthesis process of production stage was shown the highest of greenhouse gas emission. There are three ways to reduce environmental impact from the process which do not affect to the physical properties of $\mathrm{NaY}$ zeolites. First, decreasing the incubate time of $\mathrm{NaY}$ zeolites in NaY zeolites synthesis step. Second, select the appropriate size of electrical equipment. Last, choose the energy-efficient appliances in the process. All of these will lead to less GHG emission from this $\mathrm{CO}_{2}$ reduction process.

\section{Acknowledgments}

This research was funded by King Mongkut's University of Technology North Bangkok Contract no. KMUTNBNRU-58-21.

\section{References}

1. P. N. Sutar, A. Jha, P. D. Vaidya, E.Y. Kenig. Chem. Eng. J. 207, 718-724 (2012)

2. W. N. W. Salleh, A. F. Ismail, T. Matsuura, M.S. Abdullah, Separation \& Purification Reviews 40, 261-311 (2011)

3. S. Y. Lee, S. J. Park. J. Ind. Eng. Chem. 23, 1-11 (2015) 
4. C. Chen, J. Kim, D.A. Yang, W.S. Ahn, Chem. Eng. J. 168, 1134-1139 (2011)

5. T. Wiedmann, J. Minx, ISA UK Research Report. (Centre for Integrated Sustainability Analysis, Durham, UK, 2007)

6. S. Bolwig, P. Gibbon, Risø-R-Report 1719 (EN). (Risø National Laboratory for Sustainable Energy, Technical University of Denmark (DTU), 2009)

7. M. K. Chauhan, V.S. Chaudhary, S.K. Samar. Renewable and Sustainable Energy Reviews. 15, $3445-3453(2011)$

8. N. Tippayawong, K. Nakpan, International Conference on Green and Sustainable Innovation, (Thailand, 2006)

9. M.O.D.S. Dias, R. M. Filho, P. E. Mantelatto, O. Cavalett, C.E.V. Rossell, A. Bonomi, M.R.L.V. Leal. Environ. Dev. 15, 35-51 (2015)
10. P. Worathanakul, S. Kittipalarak, K. Anusarn. Adv. Mat. Res. 383, 4038-4042 (2011)

11. R. M. Mohamed, I.A. Mkhalid, M.A. Barakat. Arabian Journal of Chemistry 8, 48-53 (2015)

12. D. M. Ginter, A.T. Bell, C.J. Radke, M. L. Occelli, H. E. Robson, Synthesis of Microporous Materials, Molecular Sieves. (Van Nostrand Reinhold. New York, 1992)

13. N. Rakpasert. Preparation of Different Metals Loading on FAU Zeolite for NO Reduction (King Mongkut's University of Technology North Bangkok, Thailand, 2012) 